\section{Geology, but not on a plate}

\section{Peter J. Smith}

\section{In Suspect Terrain.}

By John McPhee.

Farrar, Straus \& Giroux: 1983. Pp.209.

$\$ 12.95$.

JOHN McPhee is a staff writer for The New Yorker who specializes in writing booklength articles that describe and interpret to the world in general the activities of particular individuals and groups within it. In 1980 , for his fifteenth investigation, he turned his attention to geologists, particularly those concerned with the Basin and Range province of the United States, to see how the earth sciences in their postrevolutionary phase differ from the traditional sort of geology that he himself had been taught in an introductory course several decades ago. The result, Basin and Range - first published by Farrar, Straus $\&$ Giroux, and earlier this year in Britain by Faber - was so successful that it led to McPhee's being feted by the North American earth-science community, though perhaps more for his uncritical, awe-struck reverence than for his ability to capture the spirit of modern geology on the page.

For what the flattered earth scientists had failed to notice was that by concentrating largely on field geology, rather than portraying today's subject as a complex interaction of fieldwork, laboratory experiment and theoretical insight, McPhee was guilty of severely understating the most important of the crossrevolutionary differences he purported to be seeking. The view of geology and geologists he offered to the outside world was thus hardly undistorted. Moreover, for British tastes, his excesses of style were hard to take, not least his tendency to generate excitement artificially by gee-whiz prose with an abundance of one-word sentences and decidedly purple passages ("salt-and-peppery charcoal-tweed savings-bank rock"). Nevertheless, the book had undoubted strengths. McPhee's set pieces on the Huttonian and (more briefly) the plate tectonic revolutions, vivid expositions aided by a nice line in extended metaphor, were beautifully executed examples of precisely what one looks for from an external interpreter with literary aspirations.

With In Suspect Terrain, his second foray into the geological world, McPhee has now confounded my worst fears by producing a far superior work of remarkable power. The tendency to overblow is here much muted and the sober strengths of the previous volume are given greater play. Largely gone, too, is McPhee's irritating habit of using geological words and concepts without explanation, thereby creating an impression of the author as an insider playing a game of one-upmanship with his non-geologist readers. The emphasis on field geology is still there, but now it has decided point - to extol the virtues of knowledge gained in the field as a counterbalance to the worst excesses of the gospel-thumping plate movers. Indeed, the geologist McPhee chose to guide him in the field, Anita Harris of the US Geological Survey, knows only too well the danger of being mesmerized by the plate people. In 1972 the pressures of the consensus led her and her colleagues to misinterpret the conodont palaeontology of an area of Pennsylvania so seriously that they came to see plate interactions where the evidence hardly warranted it - an episode that later led to painful withdrawal symptoms.

What Harris thought she had found in Pennsylvania was an exotic block, a piece of crust alien to its surroundings, a suspect terrain. Not that all suspect terrains are quite so suspect. The glacially-emplaced exotic materials with which McPhee begins and ends his spiritual journey are hardly likely to require major reinterpretation within any conceivable future. But at the

\section{Art of indoctrination}

\section{Glynn Isaac}

The Creative Explosion: An Inquiry into the Origins of Art and Religion.

By John E. Pfeiffer.

Harper\& Row: 1982. Pp.270. \$28.80, £18.50.

IN MODERN human beings the brain is the organ of culture. The intricacies of technology, communication and social interdependence would be impossible without the enlarged, elaborated brain of Homo sapiens; conversely having such a slowly grown, metabolically expensive organ would make no evolutionary sense in the absence of the complex programmes of rules and information, which make the human way of life possible. These programmes (including language) must be learned by each individual as he or she grows up. They comprise what anthropologists call culture.

Archaeology and hominid fossil skulls together provide evidence that, for the past two or three million years, the brain and culture developed as a joint system in a way that is partly analogous to the development of computer hardware and software over the past three decades. Looking at this long record as a whole, one can perhaps usefully pick out three, or maybe four, particularly significant transitions. First, two million years ago or earlier, tool-making, meateating and maybe some aspects of a basic human-like socio-economic pattern became evident; then for a very long time the record implies only very slow change: consolidation and some elaboration of these elements, but no fundamental shifts opposite extreme, the current passion for fragment tectonics and geosuturing, against which Harris so passionately inveighs in the context of the Appalachians, is altogether more insecure. At the heart of McPhee's exposition, therefore, is an extended evocation of the complex geology of the Appalachians - not a geological textbook or guidebook, but a brilliant impressionistic picture of Appalachian geology as seen on the ground acting as counterpoint to Appalachian geology perceived by the office-based global tectonicist.

"Plate tectonics is . . . a cop-out. It's what you do when you don't want to think", McPhee quotes Harris as saying. In highlighting this growing gulf between field and office geologists, McPhee is perhaps imparting to the general reader more of the spirit of modern earth sciences than some practitioners would wish. Be that as it may, he has produced by art a minor masterpiece of scientific communication.

Peter J. Smith is Reader in Earth Sciences at the Open University, and editor of Open Earth.

(unless the acquisition of control over fire is to be so classed). The second transition occurred inside the past 100,000 years and seems to involve the emergence both of anatomically "modern" human beings and of levels of social-cultural complexity such as are familiar in history and ethnography. In as far as people know about this transition at all, it is associated with the passing of the Neanderthals and the Cro Magnon forms with their Upper Palaeolithic culture. The third and fourth transitions follow hard on the heels of the second; they involve food production (farming) and the development of expanded, intensified networks of organized interdependence that we call "civilization". In a sense the third and fourth developments can be seen simply as consequences of the surge of change and diversification that followed upon the second transition.

That second transition is the least well understood, and until recently was not even subject to clear-minded attempts to formulate questions. It is in this context that John Pfeiffer's book makes its contribution.

One of the most intriguing manifestations of the Upper Pleistocene transition is the first appearance of Palaeolithic art in

\section{Solid state physics}

In 1981 Addison-Wesley published a singlevolume Encyclopedia of Physics, reviewed in Nature 290, 657 (1981). An offshoot of the parent volume which has just been published is the Concise Encyclopedia of Solid State Physics, also edited by Rita G. Lerner and George L. Trigg. The new book aims "to provide . . . a convenient and readily accessible set of resource materials" on the subject, and is available in hardback and paperback. Prices are $£ 29.60, \$ 39.50$, and $£ 17.20, \$ 22.95$ respectively. 
the archaeological record. Twenty to thirty thousand years ago the oldest known, definitive instances of such art pop up in archaeological sequences in several far-flung parts of the world, for instance South Africa, Australia and Europe.

John Pfeiffer's book deals with two questions. Why art? And why at this point in the development of the human condition? He tackles them by considering one class of art in particular, namely the representations which were painted, engraved and sculptured deep in the caves of France and Spain. He considers that the appearance of the art can best be understood in relation to new and crucial social needs. More specifically, he argues that by 30,000 years ago the volume of information to be transmitted from generation to generation in some societies had risen to levels such that indoctrination involving the dramatic presentation of materials was essential to ensure accurate uptake and further propagation. $\mathrm{He}$ argues that the representations in caves are surviving evidence of rituals which not only helped to establish the authority of those who controlled the elaborate rules but also encoded parts of the programmes in unforgettable ways.

The view that the deep-cave art of Europe was surrounded by magicoreligious ceremonies is not at all new. What is new is the explicit argument that during the Upper Pleistocene

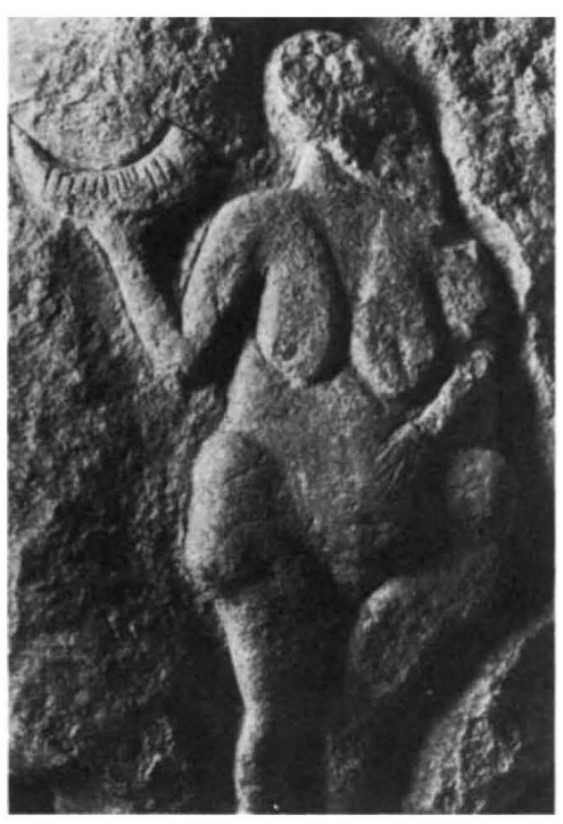

Femme à la Corne, a rock carving ascribed to the Upper Perigordian c. 23,000 years BP. The figure is $44 \mathrm{~cm}$ high and found in Laussel, a rock-shelter in the Dordogne. Photograph: B. Biraben. art; third it describes in qualitative terms features of the art, its context and other, associated traces; and fourth it advances the arguments already alluded to regarding the novel social needs of Upper Palaeolithic societies. The book is clearly intended to be read by a general as well as a scholarly audience, and the first three features have evidently been included to make the book accessible to nonarchaeologists. Expositions of the drama of the setting of the art are repeated in several parts of the book. I found this material convincing the first time but thereafter it may be that some readers, like me, will find it overdone and repetitious.

The book includes a chapter on myth, ritual and art in Australia, considered as an effective way of imprinting complex topographic, economic and social information. Pfeiffer coins the apt phrase "tribal encyclopedia" for the sum of shared information learned and transmitted in nonliterate societies.

As a non-specialist in cave art I found that the book included a variety of information that was new to me, for instance the fact that footprints of adolescents are commonly found in various deep caves where tracks are preserved. Such evidence adds plausibility to Pfeiffer's argument that initiation and indoctrination were important social functions of the art. Initiation is in fact a possible usage that had earlier been suggested by the information load to be transmitted had become so complex that special encoding and dramatic mnemomic systems become adaptive for the first time. John Pfeiffer is not alone in starting to think about such questions, his work joining the small but significant corpus of such scholars as Meg Conkey, Les Freeman, Clive Gamble, Michel Lorblanchet, Peter Ucko and Martin Wobst, among others. All of these have begun to be concerned with the problems of information flow in band societies, and with how archaeologists might monitor changing patterns in the Pleistocene. Pfeiffer's focus on the deep-cave art, however, and his argument for drama and situation as memory-imparting devices are, as far as I am aware, quite distinctive.

The book has several aspects: first it provides a brief synopsis of prehistory in general; second it presents vivid accounts of the author's own impressions and experiences in visiting the sites of deep-cave
Breuil, though without explicit consideration of the overall function of the transmission of information. Clearly key points of evidence such as the proportion of juvenile prints and other quantitative data will need to be more systematically presented by Pfeiffer, or some one else, before their implications can be fully assessed.

As indicated at the outset, the transformation of cultural systems during the upper Pleistocene seems to have been the launching pad for technological, economic, demographic and social changes that began to accelerate then, and which are still gathering speed. Pfeiffer is very probably correct in suggesting that new mechanisms for channelling the flow of complex information played a crucial part in this take-off, and he has produced a wellillustrated and provocative book about it.

Glynn Isaac is Professor of Antropology at the University of California, Berkeley.

\section{Reversals of fortune}

F.J. Vine

The Road to Jaramillo: Critical Years

of the Revolution in Earth Science.

By William Glen.

Stanford University Press: 1982. Pp.459. $\$ 37.50$.

THE MAIN title of William Glen's book is rather esoteric and perhaps a little deceptive in that it suggests a racy novel; the subtitle, on the other hand, is considerably more informative. Readers of fiction will not be entirely disappointed however for the story Glen has to tell, while firmly based in fact and soberly recounted, is a gripping one.

In essence the book covers events in three sub-disciplines of the earth sciences - geochronology, palaeomagnetism and marine geophysics - during the years 1954 to 1966; events which resulted in the definition of a geomagnetic reversal time-scale and the confirmation of the hypothesis of sea-floor spreading. Glen considers that these were the crucial developments which led rapidly to the general acceptance of the theory of continental drift and to the formulation of the modern paradigm of plate tectonics.

The Road to Jaramillo is therefore in the realm of the history and philosophy of science. It is, however, rather more than a straightforward history, based on months of work in the library, in that it draws heavily on the personal recollections, correspondence and records of the participating scientists. Thus the book provides a detailed and fascinating account not only of the way in which science proceeds but also of the way in which scientists behave while doing science.

In the 1970s several books were written on the Kuhnian type of "revolution" which took place in the earth sciences in the preceding decade. They included a book by Glen himself and were, in their different ways, faithful accounts. All of them, however, were broad-brush treatments, either designed to be of general interest or specifically aimed at undergraduates. Although the treatment in the latter part of The Road to Jaramillo is similar to that of such earlier works, the first two parts, which constitute more than three-quarters of the main text, are very different. They cover the refinement of the potassium 40 argon 40 dating technique between 1954 and 1960 , which facilitated the dating of much younger rocks than had been possible previously, and the subsequent application of this technique, together with palaeomagnetic measurements, to geologically young lava flows in order to determine their age and the direction of their "fossil" or permanent magnetization, i.e. whether it was essentially parallel (normal) or antiparallel (reverse) to the present direction of the Earth's magnetic field. In 